Case Report

\title{
Complete Remission after Sequential Therapy of Drug Eluting Beads Transarterial Chemoembolization and Liver Resection in Large Solitary Nodule Hepatocellular Carcinoma
}

\author{
Juferdy Kurniawan, ${ }^{1}$ Andri Sanityoso Sulaiman, ${ }^{1}$ Sahat Basana Romanti Ezer Matondang, \\ Toar Jean Maurice Lalisang, ${ }^{3}$ Ening Krisnuhoni, ${ }^{4}$ and Steven Zulkifly ${ }^{1}$ \\ ${ }^{1}$ Division of Hepatobiliary, Department of Internal Medicine, Faculty of Medicine, Universitas Indonesia \\ Cipto Mangunkusumo National General Hospital, Jakarta, Indonesia \\ ${ }^{2}$ Department of Radiology, Faculty of Medicine, Universitas Indonesia, Cipto Mangunkusumo National General Hospital, \\ Jakarta, Indonesia \\ ${ }^{3}$ Department of Surgery, Faculty of Medicine, Universitas Indonesia, Cipto Mangunkusumo National General Hospital, \\ Jakarta, Indonesia \\ ${ }^{4}$ Department of Pathology Anatomy, Faculty of Medicine, Universitas Indonesia, Cipto Mangunkusumo National General Hospital, \\ Jakarta, Indonesia
}

Correspondence should be addressed to Juferdy Kurniawan; juferdy.k@gmail.com

Received 3 July 2017; Accepted 23 August 2017; Published 27 September 2017

Academic Editor: Tawesak Tanwandee

Copyright (C) 2017 Juferdy Kurniawan et al. This is an open access article distributed under the Creative Commons Attribution License, which permits unrestricted use, distribution, and reproduction in any medium, provided the original work is properly cited.

Hepatocellular carcinoma (HCC) is the fifth most prevalent and the second highest cause of death among cancer. The treatment of large solitary nodule HCC is still challenging. Transarterial chemoembolization (TACE) and liver resection are two modalities of therapy in HCC management. However, recurrence rate from each therapy is relatively high. We report a case of 46-year-old man diagnosed with large solitary nodule HCC, who was treated with drug eluting bead TACE (DEB-TACE) prior to liver resection. Studies about this combination are still limited and showed various results.

\section{Introduction}

Transarterial chemoembolization (TACE) is a treatment of choice in hepatocellular carcinoma BCLC Stage B $[1,2]$. Drug eluting beads-TACE (DEB-TACE) is a relatively new drug delivery embolization and developed to optimize the delivery of chemotherapeutic agents with minimal systemic toxicity $[3,4]$. Complete response (CR) or partial response (PR) after TACE is very dependent on treatment regimen, the amount, and size of the tumor [5]. Large HCC nodule (size $\geq 5 \mathrm{~cm}$ ) had a lower CR percentage. Nodule diameter $<5 \mathrm{~cm}$ had $95 \%$ CR after first DEB-TACE. Meanwhile, only 13\% CR had been found for diameter $\geq 5 \mathrm{~cm} \mathrm{[6]}$.

Liver resection is highly recommended for HCC BCLC Stage A, with single nodule with diameter $<5 \mathrm{~cm}$ or multiple nodules (up to 3 nodules) with each diameter $<3 \mathrm{~cm}$ (Milan
Criteria) [1, 2]. However, many studies reported that liver resection is beneficial for single nodule HCC, without restriction of tumor size. Liver resection of HCC multiple nodules has been associated with lower 5 -year survival rates $[7,8]$. The median time from resection to recurrence is different from each study. The shortest and longest duration for recurrence are 22 months and 34 months, respectively, after primary resection [9-11].

Lim et al., in 2014, reported that solitary HCC with tumor size $>5 \mathrm{~cm}$ was not independent predictors of poor overall survival. The 5-year overall survival and recurrencefree survival rates of size between 5 and $10 \mathrm{~cm}$ were $58 \%$ and $26 \%$, respectively, and size $>10 \mathrm{~cm} 53 \%$ and $24 \%$, respectively [12]. Retrospective analysis of liver resection for large solitary HCC by Zhao et al. in 2016 showed that 5 -year overall survival and disease-free survival were $43 \%$ and $47 \%$, respectively [13]. 

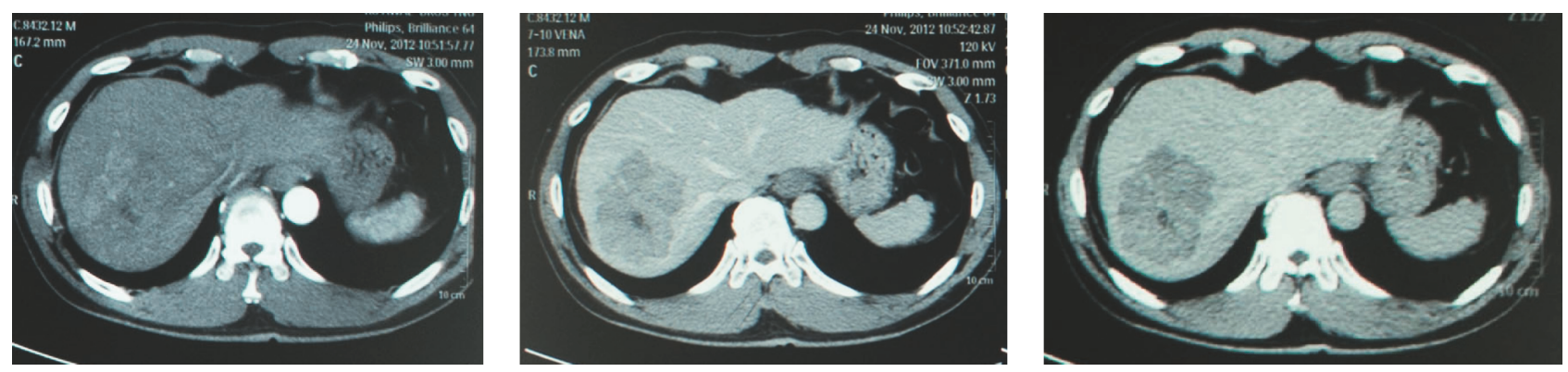

FIgURE 1: Arterial, venous, and delayed phase of Abdominal CT Scan after diagnosis (November 2012).
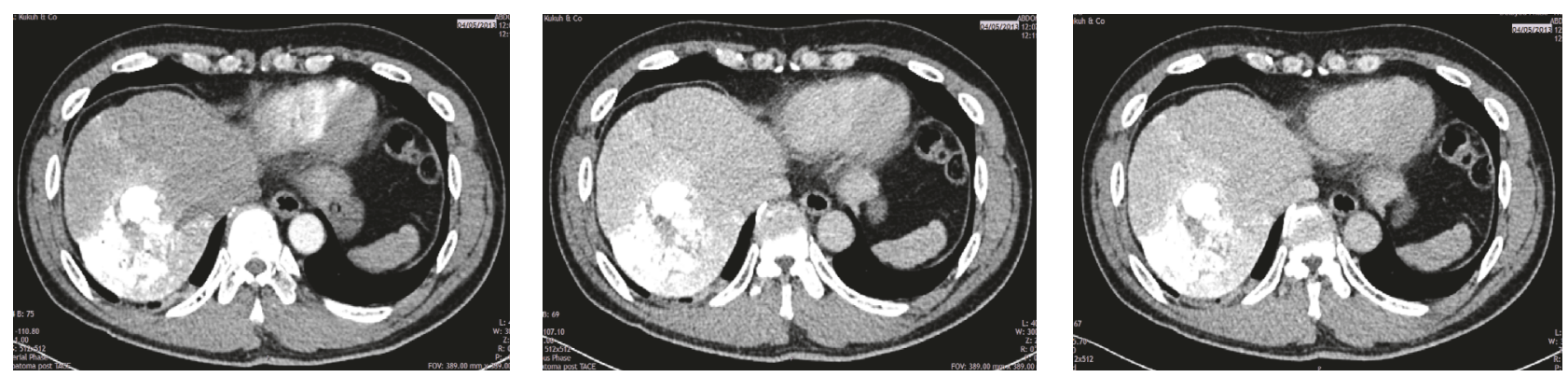

Figure 2: Arterial, venous, and delayed phase of Abdominal CT Scan after first DEB-TACE (January 2013).

Zhao et al. also reported the postoperative complications were found in $21 \%$ patients, including ascites $(21.21 \%)$, transient hepatic dysfunction $(9.9 \%)$, bile leakage $(7.7 \%)$, and liver failure $(4.4 \%)$. Thirty-day mortality after resection was $2.2 \%$ due to liver failure [13]. Recent study by Chen et al. compared the postoperative complications between solitary $\mathrm{HCC}<10 \mathrm{~cm}$ and $\geq 10 \mathrm{~cm}$. Total complications in HCC $\geq$ $10 \mathrm{~cm}$ were $39.1 \%$ and higher than $\mathrm{HCC}<10 \mathrm{~cm}(29.8 \%)$. Liver failure occurred in 1\% (2 patients) and $4 \%$ ( 1 patient), respectively [14].

There are limited studies about postsurgical complication of liver resection of large solitary HCC after TACE. Recent study reported postoperative complications were found in $59.2 \%$ (29 patients), including bile leakage ( 2 patients) and gastrointestinal hemorrhage (1 patient). The alteration of liver function was recovered in 1 month [15].

\section{Case Presentation}

A man, 46 years old, came to his gastroenterohepatology consultant with chief complaint of abdominal pain on the right upper quadrant. He was diagnosed with hepatocellular carcinoma and chronic hepatitis B. The patient then underwent the 3-phase Abdominal CT Scan examination in November 2012 (Figure 1). The radiologic examination findings revealed an $8 \mathrm{~cm}$ solitary nodule $\mathrm{HCC}$ in segment 7 . He was classified into BCLC Stage B with Child Pugh (CP) score A. The drug eluting bead (DEB) TACE procedure was then planned for the patient. He also received a lamivudine $100 \mathrm{mg}$ once daily for chronic hepatitis B.

The first DEB-TACE was performed in January 2013. Evaluation of the tumor was assessed by using 3-phase
Abdominal CT Scan a month later. It showed minimal hypervascular lesion from middle hepatic artery (Figure 2). DEB-TACE was planned for the patient for the second time. Second DEB-TACE was performed 4 months later in May 2013 and 3-phase Abdominal CT Scan after TACE showed reduction of tumor size to $3 \times 4 \mathrm{~cm}$ (Figure 3 ).

In November 2013, liver resection was performed in segments 6,7 , and 8 of the liver. The tissue was sent to pathology anatomy department for histopathological examination. The microscopic findings of resection showed HCC grade III. Radiographic examination of 4 months after liver resection showed no abnormality (Figure 4). Three years after resection, the patient underwent the Abdominal CT Scan examination and no tumor was found. (Figure 5).

\section{Discussion}

The research about TACE prior to liver resection is very limited. Small trial by Gerunda et al., in 2000, compared 20 HCC patients who underwent resection to TACE prior to resection. Early recurrence ( $<24$ months) and late recurrence (>24 months) were found higher in resection alone group, with $59 \%$ and $10 \%$ compared to TACE and resection, with $20 \%$ and $10 \%$, respectively [16].

Another study reported there are difference of 1-, 2-, and 5-year overall survival rates between the TACE prior to surgery and resection alone group $(p=0.11)$. Contrary to previous study, the 1-, 2-, and 5-year recurrence-free interval were higher in resection alone $(97 \%, 83 \%$, and $45 \%$, resp.) compared to TACE-surgery group (58\%, 36\%, and 7\%, resp.) with $p=0.01$ [17]. TACE procedure induced tumor downstaging or necrosis and hypothesized to be associated with 

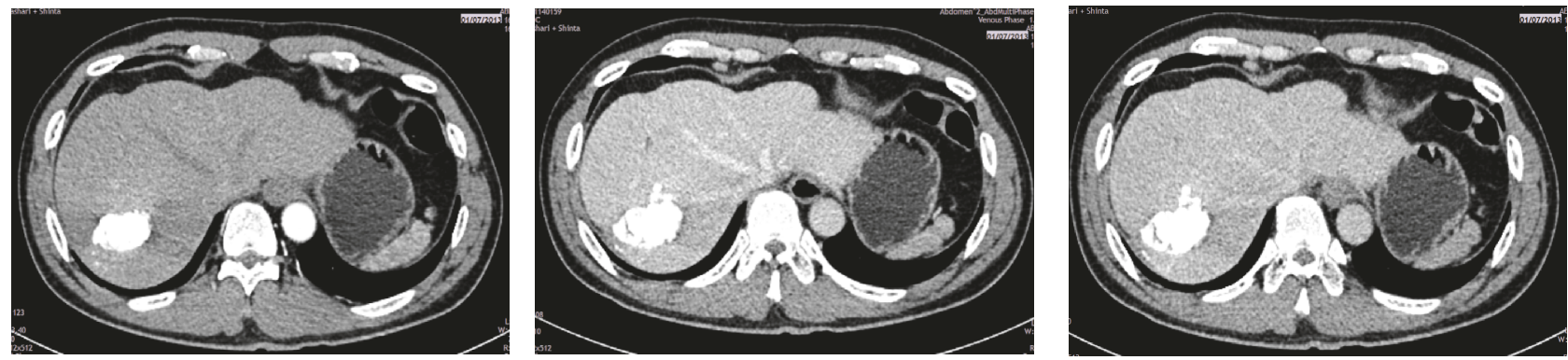

FIGURE 3: Arterial, venous, and delayed phase of Abdominal CT Scan after second DEB-TACE (May 2013).
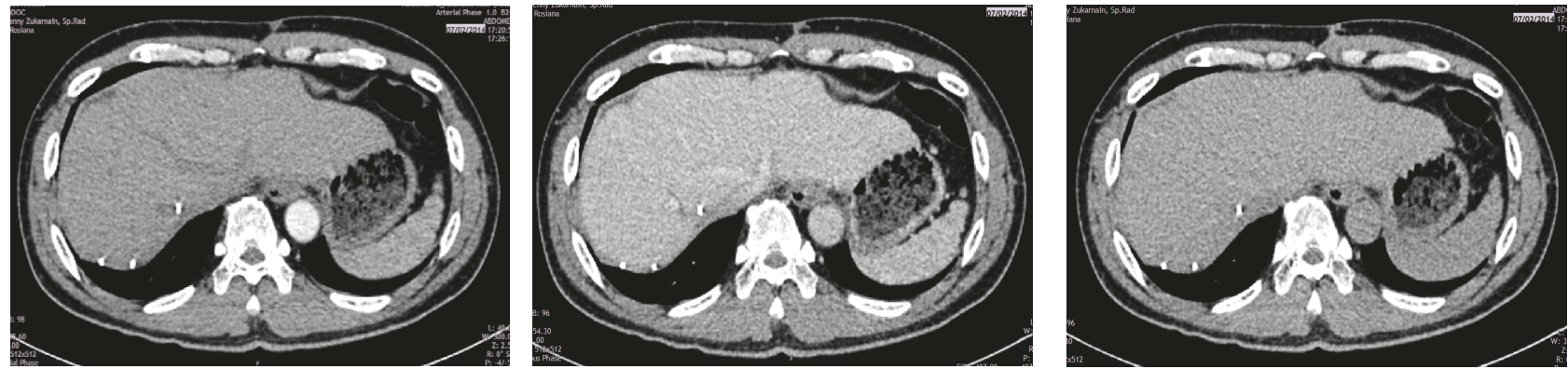

FIgURE 4: Arterial, venous, and delayed phase of Abdominal CT Scan 4 months after surgical resection (February 2014).
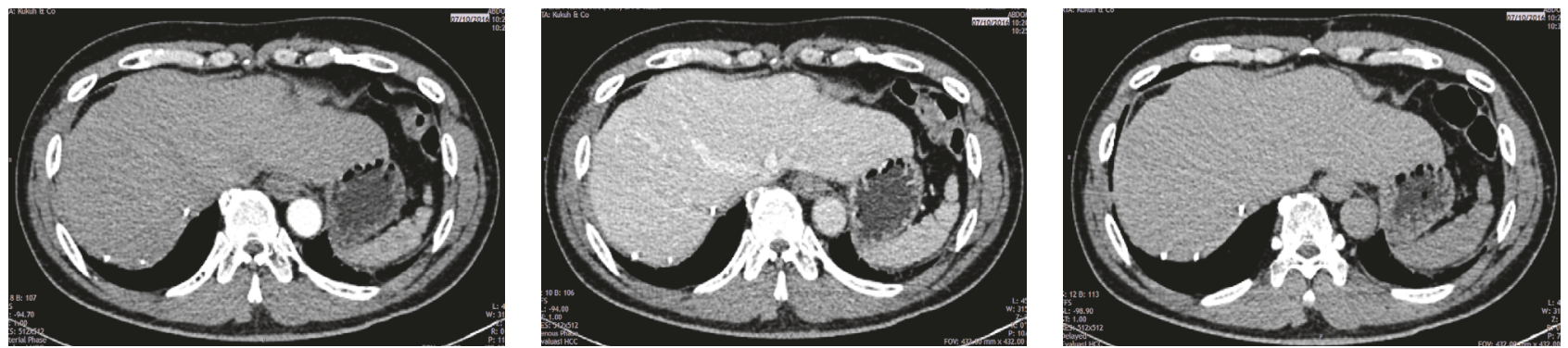

FIGURE 5: Arterial, venous, and delayed phase of Abdominal CT Scan 3 years after surgical resection (November 2016).

improvement of disease-free survival. The higher recurrence rate in TACE-surgical group was especially found in patients with initial resectable HCC. It was suggested that preoperative TACE might induce incomplete necrosis, resulting in hematogenous spread of residual tumor cells after liver resection, and caused recurrences $[17,18]$.

However, recent study in 2017 compared TACE prior to surgery (49 patients) and TACE alone in large/multifocal HCC (61 patients). All of the patients were classified in BCLC Stage B. The mean initial tumor in TACE + surgery and TACE group is $7.22 \pm 3.18 \mathrm{~cm}$ and $6.80 \pm 3.35 \mathrm{~cm}$, respectively. However, the number of tumors was not limited to solitary tumor. The 1-, 2-, and 3-year overall survival rates in TACE + surgery group were $89.8 \%, 79.4 \%$, and $59.1 \%$, respectively, and in TACE alone were $75.1 \%, 61.5 \%$, and $15.1 \%$, respectively. In univariate analysis, solitary tumor was associated with higher overall survival, with $p=0.012$ [15].
DEB-TACE has been found to be more effective for large nodule $(>5 \mathrm{~cm})$ compared to cTACE. In subgroup analysis of Asian patients who received DEB-TACE with size $>5 \mathrm{~cm}$, DEB-TACE was reported to have significantly higher objective response compared to CTACE. The largest tumor size included in this study was $12 \mathrm{~cm}$. Around $16.3 \%$ and $66.6 \%$ patients with large tumor size achieved CR and PR, respectively, in DEB-TACE group [16].

However, there are no publications that studied about the efficacy of DEB-TACE prior to surgery in large solitary nodule HCC. This case report presents a complete remission after 3 years of solitary large nodule of HCC with sequential therapy of DEB-TACE and liver resection. However, larger studies with longer duration are needed to find the efficacy, survival rates, and tumor recurrence.

For conclusion, the treatment of HCC with solitary large nodule is still challenging for clinicians. HCC patients who 
underwent TACE before resection have better overall survival, but it might have higher risk for recurrence compared to resection alone. TACE is safe procedure and effective for large HCC. DEB-TACE prior to liver surgery can be suggested for therapy of large solitary nodule of HCC.

\section{Consent}

The patient's informed consent was obtained for case publication.

\section{Conflicts of Interest}

The authors declare that there are no conflicts of interest regarding the publication of this paper.

\section{References}

[1] J. Bruix and M. Sherman, "Management of hepatocellular carcinoma: an update," Hepatology, vol. 53, no. 3, pp. 1020-1022, 2011.

[2] European Association for the Study of The Liver, "EASLEORTC Clinical Practice Guidelines: management of hepatocellular carcinoma," European Journal of Cancer, vol. 48, no. 5, pp. 599-641, 2012.

[3] W. Sieghart, F. Hucke, and M. Peck-Radosavljevic, "Transarterial chemoembolization: modalities, indication, and patient selection," Journal of Hepatology, vol. 62, no. 5, pp. 1187-1195, 2015.

[4] J. Lammer, K. Malagari, T. Vogl et al., "Prospective randomized study of doxorubicin-eluting-bead embolization in the treatment of hepatocellular carcinoma: results of the PRECISION V study," CardioVascular and Interventional Radiology, vol. 33, no. 1, pp. 41-52, 2010.

[5] R. Lencioni and J. M. Llovet, "Modified recist (mRECIST) assessment for hepatocellular carcinoma," Seminars in Liver Disease, vol. 30, no. 1, pp. 52-60, 2010.

[6] G. Vesselle, C. Quirier-Leleu, S. Velasco et al., "Predictive factors for complete response of chemoembolization with drug-eluting beads (DEB-TACE) for hepatocellular carcinoma," European Radiology, vol. 26, no. 6, pp. 1640-1648, 2016.

[7] A. A. Madkhali, Z. T. Fadel, M. M. Aljiffry, and M. M. Hassanain, "Surgical treatment for hepatocellular carcinoma," Saudi Journal of Gastroenterology, vol. 21, no. 1, pp. 11-17, 2015.

[8] H. Nakayama and T. Takayama, "Role of surgical resection for hepatocellular carcinoma based on Japanese clinical guidelines for hepatocellular carcinoma," World Journal of Hepatology, vol. 7, no. 2, pp. 261-269, 2015.

[9] P. Tabrizian, G. Jibara, B. Shrager, M. Schwartz, and S. Roayaie, "Recurrence of hepatocellular cancer after resection: patterns, treatments, and prognosis," Annals of Surgery, vol. 261, no. 5, pp. 947-955, 2015.

[10] H. Lang, G. C. Sotiropoulos, E. I. Brokalaki et al., "Survival and recurrence rates after resection for hepatocellular carcinoma in noncirrhotic livers," Journal of the American College of Surgeons, vol. 205, no. 1, pp. 27-36, 2007.

[11] S. A. Shah, S. P. Cleary, A. C. Wei et al., "Recurrence after liver resection for hepatocellular carcinoma: Risk factors, treatment, and outcomes," Surgery, vol. 141, no. 3, pp. 330-339, 2007.

[12] C. Lim, Y. Mise, Y. Sakamoto et al., "Above $5 \mathrm{~cm}$, size does not matter anymore in patients with hepatocellular carcinoma," World journal of surgery, vol. 38, no. 11, pp. 2910-2918, 2014.
[13] H. C. Zhao, R. L. Wu, F. B. Liu, Y. Z. Zhao, G. B. Wang, Z. G. Zhang et al., "A retrospective analysis of long term outcomes in patients undergoing hepatic resection for large $(>5 \mathrm{~cm})$ hepatocellular carcinoma," HPB: The Official Journal of The International Hepato Pancreato Biliary Association, vol. 18, pp. 943-949, 2016.

[14] J.-H. Chen, C.-K. Wei, C.-H. Lee, C.-M. Chang, T.-W. Hsu, and W.-Y. Yin, "The safety and adequacy of resection on hepatocellular carcinoma larger than $10 \mathrm{~cm}$ : A retrospective study over 10years," Annals of Medicine and Surgery, vol. 4, no. 2, pp. 193-199, 2015.

[15] J. Chen, L. Lai, Q. Lin et al., "Hepatic resection after transarterial chemoembolization increases overall survival in large/ multifocal hepatocellular carcinoma: A retrospective cohort study," Oncotarget, vol. 8, no. 1, pp. 408-417, 2017.

[16] G. E. Gerunda, D. Neri, R. Merenda et al., "Role of transarterial chemoembolization before liver resection for hepatocarcinoma," Liver Transplantation, vol. 6, no. 5, pp. 619-626, 2000.

[17] J. Y. Kang, M. S. Choi, S. J. Kim et al., "Long-term outcome of preoperative transarterial chemoembolization and hepatic resection in patients with hepatocellular carcinoma.", The Korean journal of hepatology, vol. 16, no. 4, pp. 383-388, 2010.

[18] H. Nishikawa, A. Arimoto, T. Wakasa, R. Kita, T. Kimura, and Y. Osaki, "Effect of transcatheter arterial chemoembolization prior to surgical resection for hepatocellular carcinoma," International Journal of Oncology, vol. 42, no. 1, pp. 151-160, 2013. 


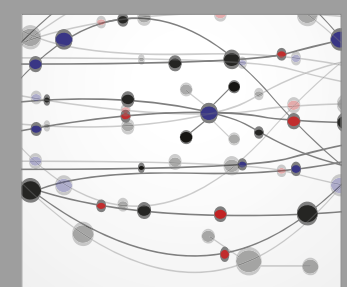

The Scientific World Journal
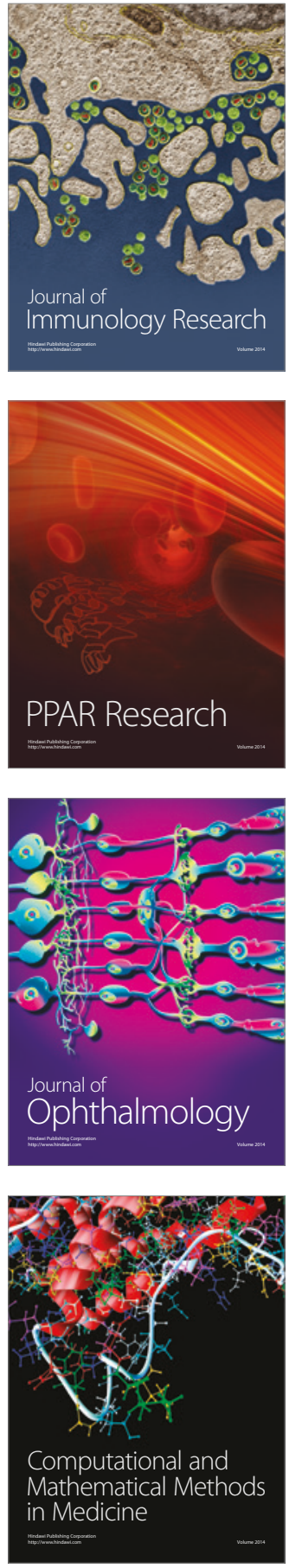

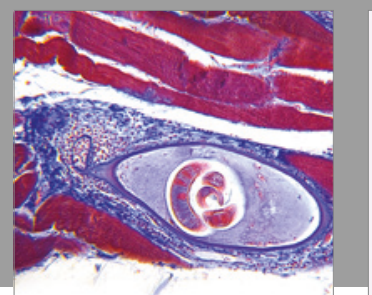

Gastroenterology Research and Practice
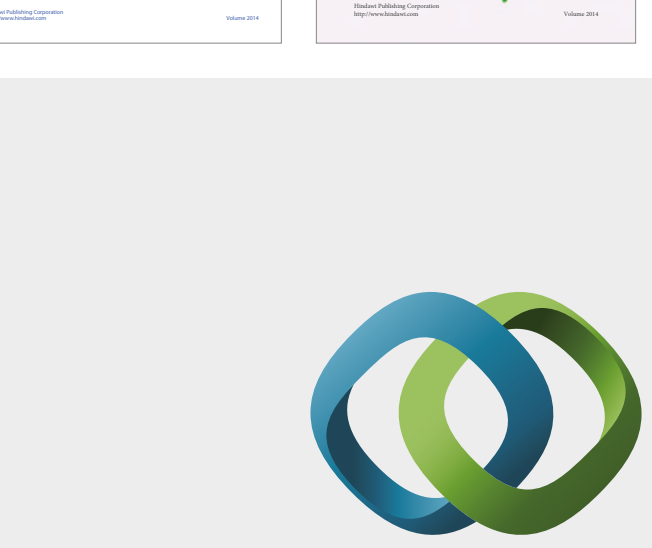

\section{Hindawi}

Submit your manuscripts at

https://www.hindawi.com
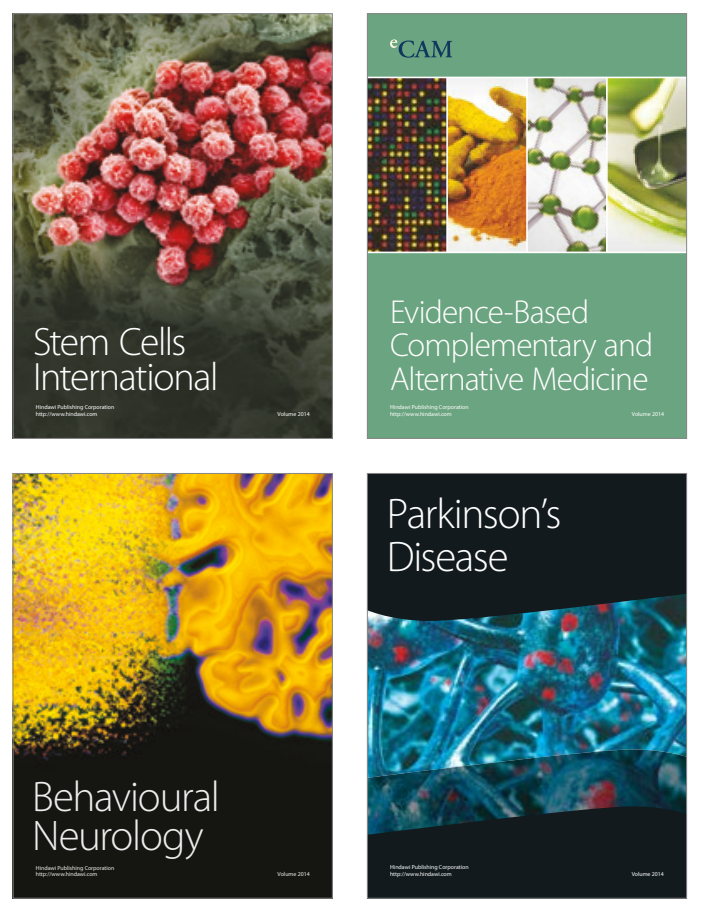
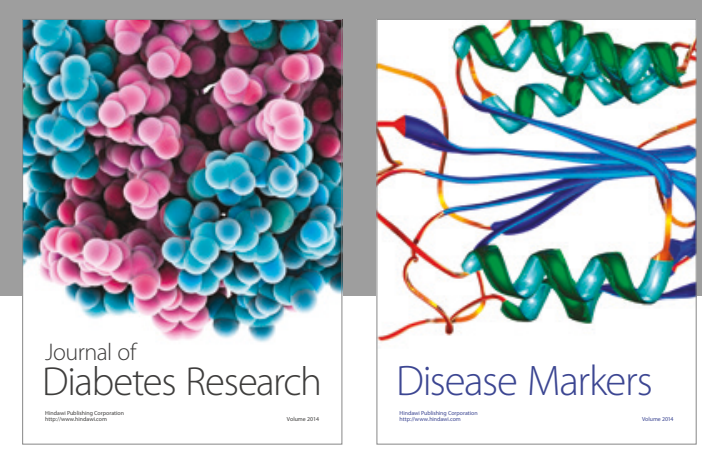

Disease Markers
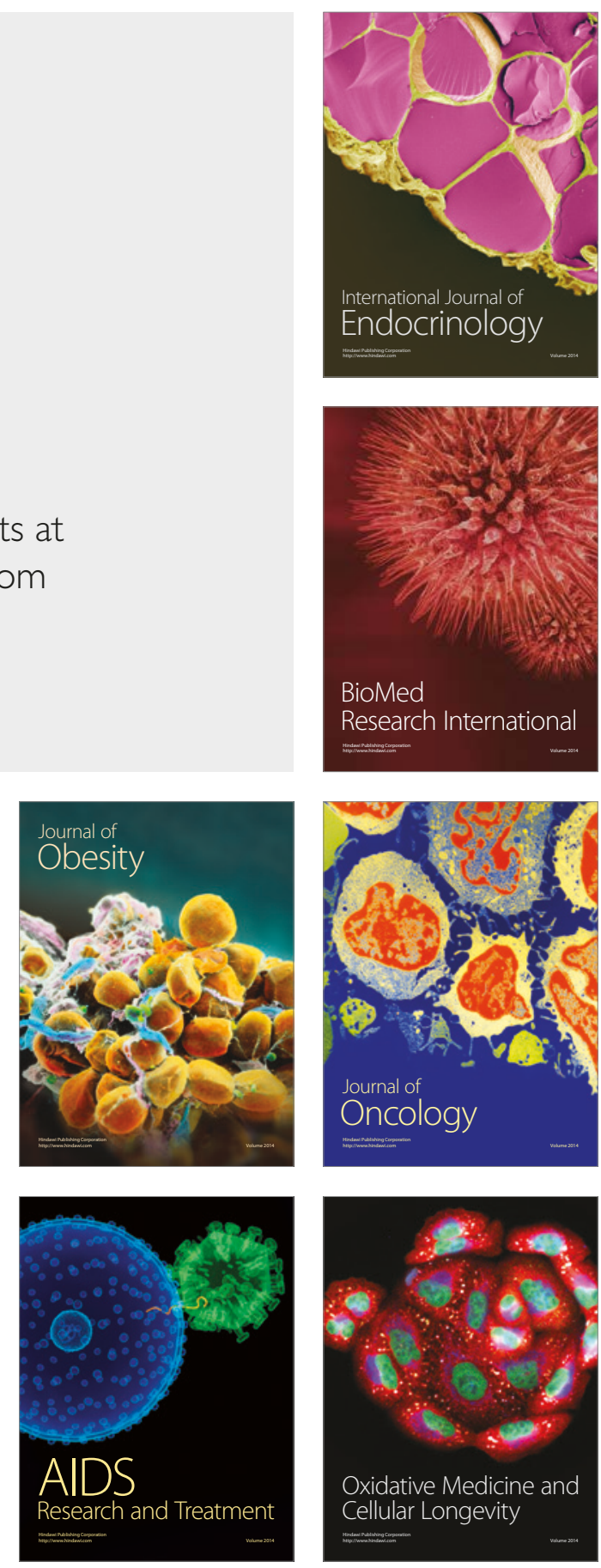